\title{
On the Globalization and Fragmentation of the Modern World
}

\author{
Kamaludin Gadzhiev \\ The National Research Institute of World Economy and International Relations, Russian Academy of Sciences, Moscow, Russia \\ Email address: \\ k.gajiev@rambler.ru \\ To cite this article: \\ Kamaludin Gadzhiev. On the Globalization and Fragmentation of the Modern World. Journal of Political Science and International \\ Relations. Vol. 2, No. 1, 2019, pp. 1-10. doi: 10.11648/j.jpsir.20190201.11
}

Received: October 16, 2018; Accepted: February 13, 2019; Published: March 5, 2019

\begin{abstract}
In the article an attempt is made to reveal and analyze some key, in the author's opinion, factors underlying the controversial nature of globalization. Having considered some of the most significant consequences of globalization from the point of view of the unity of the modern world, the main attention is focused on the main factors, nature, systemic and structural components of those tendencies and processes that resulted in the opposite tendency to undermine this unity. The author sees the paradox of globalization in the fact that, due to a complex of factors determining the geopolitical picture of the modern world, it has created the conditions for localization, re-nationalization, fragmentation and deconstruction of the modern world. The trend of de-sovereignization of national states is replaced by the trend of their re-sovereignization. The most significant examples in support of this thesis are the processes of disintegration of multinational states and the formation of many new national states, the growing influence of nationalist and separatist movements, organizations, parties that oppose globalism, universalism and transnationalism. One of their manifestations became the phenomenon of building various fences and walls separating peoples, countries and states from each other. On the basis of these and a whole complex of related factors, trends and processes, it was concluded that in the modern world, a single humanity with a complex of values, ideals, and interests common to all nations and states can be imagined, figuratively speaking, from a bird's flight. In reality, the unity of humankind is an abstract, metaphorical concept, which is intended to unite very heterogeneous, contradictory, conflicting, cultural and civilizational circles, peoples, states, communities pursuing different, sometimes opposite goals and interests as a whole. Of course, they have a complex of common fundamental interests, from the protection of which depends the very physical existence of the mankind. The combination of these two seemingly opposing principles forms the basis of the formula "fragmentation in unity, or unity in fragmentation".
\end{abstract}

Keywords: Globalization, Fragmentation, Humanity, Unity, Sovereignty, World Order

\section{Introduction}

It is obvious that in this field of political science in the United States and to a lesser extent in Russia, many works have appeared in which the globalization is viewed from different angles. One listing of them would take a substantial part of this work. Being grateful to all the authors, with whose works the author of this article is somehow familiar, the article focuses on those aspects of this problem that, it seems, still have not received coverage adequate to their significance. At the same time, it should be emphasized that, as a rule, the place and role of globalization is often viewed separately from the information revolution. The fact is that in many respects it largely determines the systemic and structural components of globalization, its nature, vectors, purposes. Therefore, this problem, especially with regard to fragmentation, should be analyzed in close relationship of these two phenomena that determine current position and prospects of the modern world.

Globalization and the information revolution led to tectonic shifts in the basic structures of social life, first of all, in the West, and then in the rest of the world. It was assumed that globalization would lead to the unification of the modern world on the principles of liberalism, market economy and the "Washington consensus". Indeed, information technologies and globalization contribute to the intensification of economic, political, cultural ties between peoples, countries, regions, the processes of integration, the 
unity of all mankind. It is impossible not to admit the obvious fact that the so-called faults of civilizations are eroding - in the West there is a lot of East, and in the East - a lot of West.

In the most important spheres of public life, there is a tendency towards an unprecedented interpenetration of domestic and foreign policies. The significance of the domestic political consequences of foreign policy and the foreign policy consequences of domestic policy is growing. The principle of the exclusive jurisdiction of the national state over its territory is, in fact, increasingly questioned. There is an increasingly clear tendency to revise the provisions of Art. 2 (7) of the UN Charter, which does not allow interference in the internal affairs of each other's states. In stating these and other related tendencies, some authors try to justify the conclusion that the sovereignty of a national state turns into a relic of the past. They talk about the possibility of a significant weakening of the role of the national state on the world stage, even of its disappearance. It is asserted that the process of denationalization of peoples is underway, which, naturally, will make the national identity a relic of the past.

As a rule, globalization is perceived by many authors as a process of unavoidable integration and homogenization of the modern world, implying the need to develop and implement new forms of interstate cooperation, leading, in turn, to the establishment of a global governance system. As noted by F.J. Serni and A. Pritchard, such a statement of the issue in the treatment of the columnist of The New York Times T.L. Friedman, includes "economic globalization, the ideological hegemony of neoliberalism, socio-cultural convergence, technological innovation and change, liberal internationalism and global governance, and the emergence of a certain type of the so-called "flat world". From such an interpretation, in their opinion, "normative calls for a world state seen to be the only means by which order and justice can be maintained at a global level" [3].

One cannot deny the fact that globalization and the information revolution have become a factor that contributed to fundamental shifts in the system and infrastructure components of the modern world. These shifts are obvious, and there seems to be no point in dwelling on them in any detail. Here it is enough to mention in a very brief form only some of them.

There are tendencies toward erosion of the territorial imperative, state borders, national and state identity. It seems that modern mankind, metaphorically speaking, turns into a kind of global communal megalopolis, where the boundaries of the life space of collectives, communities, peoples on the local, subnational, national, supranational levels are steadily shrinking. As a result, many peoples face the prospect of losing their national, local, regional, cultural, historical identities. For many people, it is difficult to answer the sacramental question: "Who are we?"

It seems that experiencing a crisis is not one form or another of the state, but the phenomenon of the state itself. In such a situation, the question arises: did not the sovereign national state become did not the sovereign national state become property of history?

\section{The Reverse Side of Globalization}

To find the right answer to this question, it is necessary to look at another equally important aspect of globalization and the information revolution. This is the opposite trend of fragmentation and deconstruction of the modern world.

The fact is that in conditions in which nations, as never before, have come closer and are bound by many ties with each other, the relations between them are becoming increasingly contradictory and conflicting. However, such a situation seems a paradox only at first glance. In fact, the paradox of globalization is rooted in its contradictory nature and purpose, and, last but not least, in its incorrect, or rather erroneous, interpretations.

As the experience of recent decades shows, globalization and the information revolution, on the one hand, seem to level, blur or even eliminate the borders that divide peoples, states, cultures, national and ethnic identities, etc. On the other hand, they expand the possibilities of choosing the ways, forms, means of realization laid down in each individual, collective, people, culture, state, civilization. It was found that the processes of globalization, universalization and the associated cosmopolitanization and a unification of life styles, forms of behavior, fashion, etc. generate among nations, countries and regions, with great probability, the opposite reaction to the revival and intensification of adherence to national cultural values and traditions, the desire to underline their uniqueness, difference, etc. Moreover, the stronger the tendency towards universalization and unification of the external aspects of life, the more people tend to value such internal, characterological components as traditions, religion, language, culture, identity and, accordingly, the national and cultural identity of their people. On the one hand, conditions are created for the formation of a transnational global world system, where all peoples and states form a single, indivisible whole. On the other hand, paradoxical, at first glance, globalization and the information revolution are becoming a powerful factor of localization, renationalisation, resovereignization, fragmentation and deconstruction of the modern world, bringing national, religious, socio-cultural, politico-cultural and other differences to the fore.

They became the basis by which the reverse trend unfolded - the disintegration of multinational states, their fragmentation and the formation of a multitude of new nation states. Today, nationalist and separatist movements, organizations, parties that oppose globalism, universalism and transnationalism are increasingly gaining popularity and influence, trying to defend the traditional values and institutions that underlie the Judeo-Christian civilization. The trend of de-suveignization of national states, which prevailed in the first two decades after the collapse of the USSR and the end of the bipolar world order, is replaced by the trend of their re-sovereignization.

As a result, the vocabulary of political science includes 
terms and expressions like "functional differentiation", "deterritorialization", "neomedievalism", etc. It seems that the terms offered by the Polish researcher Z. Bauman and J. Rosenau are more acceptable. According to Bauman, integration and fragmentation, globalization and "territorialization" of the world are interrelated and are different sides of a single process. Therefore, together with him it seems appropriate to use the term "glocalization," which refers to a process that brings together the tendencies of globalization and localization [1]. J. Rosenau regards globalization as a process based on two opposite processes: centralization, integration and globalization, on the one hand, decentralization, fragmentation and localization, on the other. To denote the interconnection of these two principles, he proposes the ungainly and contrived word "fragmegration" "for the inextricable links between the individual and societal tendencies to integrate across boundaries that are the hallmark of globalization and the counter tendencies toward fragmentation that are fomented by localizing resistances to boundary-spanning activities" [15].

A clear idea of the validity of these arguments can be obtained from the example of European integration. Despite the obvious achievements of the European Union in this direction, as political integration expanded, the contradictions between the supra-national and the national principles of the management system of the most important spheres of public life began to show themselves to an ever-increasing degree. This was already evidenced by the failure of the draft constitution of the European Union in 2005, which was intended to legitimize the concentration of rather serious powers in the supranational institutions of Brussels.

The increasing difficulties that Brussels faces are particularly evident in the discontent of an ever growing segment of the population in some form or intensity in almost all EU member states. The most obvious examples in this regard include referendums on the separation of Scotland from England in September 18, 2014, Catalonia from Spain on October 1, 1917, Brexit Britain on June 23, 2016 from the European Union, right-wing or new-right movements, organizations, parties, joint under the common name of "eurosceptics" and offering their alternative to the prospects of the peoples of Europe. From elections to elections, increasing their weight and influence in political life, they oppose the very political integration, as it really is, for the return, as they say, to the national governments of those elements of national sovereignty that are transferred to Brussels.

From this point of view, the so-called informal association "Initiative of the Three Seas", which unites 12 states located in the geo-political space between the Adriatic, Baltic and Black Seas, can be considered to be an indicator of those cracks that arise on the political landscape of the European Union. The association includes 12 countries: Austria, Bulgaria, Croatia, Czech Republic, Estonia, Hungary, Latvia, Lithuania, Poland, Romania, Slovakia and Slovenia. By the way, 11 out of them are members of NATO. Given a certain confluence of circumstances, this association, combined with the alleged policy of a "Europe of two speeds" of integration proposed by the leading states of Old Europe, brings to the EU elements of contradictions and divisions.

One of the stumbling blocks in the relationship between the Old and the New Europe was the question of quoting the number of immigrants. In spite of all the contradictions, disputes and discussions, the solution of this issue acceptable to all parties seems vague in the foreseeable future, although the European Commission launched a mechanism for Brussels to impose fines and even economic sanctions on the most implacable countries, such as Poland, the Czech Republic and Hungary, for their terrible refusal to accept a quota system for immigrants. At the same time, for its part, the Vishegrad Four (Poland, Czech Republic, Slovakia and Hungary) stated that they will defend their rights in the European Court.

Perhaps it would be an exaggeration to say that in reality, the shadow is wandering around Europe, the specter of nationalism, which is no longer a shadow, but the reality is the specter of separatism. In this vein, with certain reservations, one can argue about the failure of attempts to create a single European identity for citizens of the member states of the Union. This goal was put in view of the unilateral, not always corresponding to the real state of things interpretation of the possibilities and prospects of the draft of the Maastricht Treaty of 1992 on the creation of the European Union on the path of political integration. It was essentially about the actual denationalization of national identity and the formation on its basis of a single European identity.

It was essentially about the actual denationalization actual denationalization of national identity and the formation on its basis of a united European identity. And this, in turn, implies united citizenship of the European Union and, consequently, of a united European people or a united European nation. The strength, vitality, prospects of Europe were based on the richness and diversity of cultures, languages, national identities. Each of the members of the European Union joined it with its historical, spiritual, socio-cultural, politicocultural heritage. So far, there have not been any serious signs that would indicate the formation of a single "people of Europe" and the possibility of rejecting in the foreseeable future the majority of French, British, Germans, Poles, Hungarians, and others from their national identity. In this sense, we can agree with Secretary General of the Council of Europe T. Jagland, who believes that "there is Europe, but it consists of different parts and differs from country to country in a multipolarity that must be taken into account" [4].

It is obvious that the real unity of Europe in the form in which it appeared to the initiators of political integration with the goal of creating a super-state in the form of the United States of Europe or in some other format has not yet been traced.

After the victory of D. Trump in the presidential elections in November 2016 and as a result of his first visit to Europe, the cracks in relations between the Old Europe and the USA began to appear, although they should be treated with some caution. In this vein, we can assess the Trump's refusal from 
the planned Transatlantic trade and investment partnership between the European Union and the United States. He declared the US withdrawal from the Trans-Pacific partnership between the twelve countries of the Asia-Pacific region, as well as from the Paris agreement on climate. Trump demanded revision of the terms of the North American Free Trade Agreement and threatened to impose duties on steel imports. In fact, attempts are being made to launch a new cycle of protectionism and a departure from the principles of free trade of the WTO.

An additional contribution to these trends was made by Trump's criticism of the leaders of the countries - America's closest allies in NATO on the issue of insufficient allocation of funds for defense. Before that, there was a very impressive exit from the European Union of Great Britain - the so-called Brexit, which Trump enthusiastically supported. He also supported the above-mentioned association "Initiative of the Three Seas". In connection with the combination of these two landmark events, some authors have started talking about cracks in relations not just with America, but with the AngloSaxon world as a whole.

Between the European Union and the United States there were also problems on the issue of Washington's unilateral sanctions against Russia. On this background, there is an increasingly pronounced tendency to ferment in the minds of the leaders of European countries. Those new rules of the game that Trump suggested to Europe prompted the Chancellor of the Federal Republic of Germany A. Merkel, speaking at the pre-election rally on May 28, 2017, to state: "The times when we could fully rely on others seem to be ending, and I felt it in the last few days. We Europeans must truly take our destiny into our own hands. Of course, we need friendly relations with the United States, with Britain and with other neighbors, including Russia. But we must fight for our own future" [14]. This point of view, verbally or by default, is supported by the leaders of other states of the Old Europe.

The Berlin Wall in its material embodiment was really destroyed, the fragments and bricks from it were taken perhaps to all corners of the world. But the space, freed from walls and barriers, despite the processes of globalization and the information revolution did not become a convenient platform for the unification of peoples. What seemed to be impossible became possible: the trend of the construction of new real and metaphorically understood fences and walls along the borders separating peoples, states, regions began. Here, of course, it is important to speak first of all about the young European countries, which are trying to block off Russia not only with various kinds of economic sanctions and information and ideological confrontation, but also ditches, barbed wire fences, walls with video surveillance systems.

The first EU country that created the border wall was Greece, which in 2012 was fenced off by a 10-kilometer fence 4 meters high from Turkey. The experience of Greece was adopted by other EU countries. Hungary began to build barriers on the borders with Serbia and Croatia, Austria undertook the erection of a fence on the border with Slovenia, and Slovenia in turn decided to wall off from Croatia. In addition, in November 2015 Macedonia began construction of a fence on its border with Greece. Justifying the necessity of building a wall along the border with Russia, the head of the Ministry of Internal Affairs of Estonia H. Pevkur stated: "Estonia needs a modern state border, worthy of being the external border of Europe and NATO". It is planned to erect a fence with a height of $2.5 \mathrm{~m}$ and a length of approximately $90 \mathrm{~km}$. The wall on the Latvian-Russian border is planned at a height of 2.7 and a length of $92 \mathrm{~km}$. Latvia undertakes to build also a fence along the border with Belarus. Lithuania decided to isolate itself from the Kaliningrad region with its own fence, $44.6 \mathrm{~km}$ long and 2 meters high. Thus, the Spanish newspaper La Vanguardia not without reason argues: "The present time, we can say with certainty, historians will be called the time of the walls. Just as 1989 was remembered as the year of the fall of the Berlin Wall, 1991 was remembered by the disappearance of the USSR, and 1993 - by the entry into force of the Maastricht Agreement and the creation of that European Union that is now living the last few months: the EU without internal borders". It is very difficult not to agree with the publication, which regretfully states: "... the countries of the Community cease to trust each other: Europe increasingly feels itself as an animal that has fallen into a cage. More precisely, driven himself into this cage" [8].

After all, what is happening in the European Union does not fit in with the initial attitudes towards political integration of the countries of the region through the formation of a super-state in the form of the United States of Europe with a single European nation, a single identity, a single citizenship, a common currency, etc.

Ukraine is not far behind the Baltic countries, which, after the reunion of the Crimea with Russia, began simultaneously digging a ditch and erecting two thousand $\mathrm{km}$ long fence which is intended to isolate her from Russia. Norway is considering its fence along the 200-kilometer border with Russia, and Poland - along the borders with Belarus and Ukraine.

Back in 2004, the Israeli leadership decided to isolate Palestine by a $700 \mathrm{~km}$ wall. Ten years later, Turkey began building a $500 \mathrm{~km}$ wall with Syria, and Saudi Arabia - in 2015 on the border $900 \mathrm{~km}$ long with Iraq. It should also be noted the grandiose project for the construction of a 4,5meter-high wall on the US-Mexico border, started under President George W. Bush Jr. The current US President, D. Trump, significantly expanded this project, giving it a strategic character.

Here are just some examples of the phenomenon of fence and wall construction, which, is enough to verify the reality of the trends of fragmentation and disintegration of the modern globalizing world. Obviously, in the event of any serious conflict, these artificial iron or bamboo curtains in the form of fences, walls, ditches, etc., will not have any importance, since radically changed the factors, forms, content, nature of contradictions, conflicts, wars between 
nations, and forms, methods, means of resolving them.

Demographic and migration processes contribute to changing the ethno-national picture of the world. In this sense, the complex of processes and phenomena occurring on a world scale, as already noted, can be viewed as a two-way process, on the one hand, the partial westernization of the East in the economic and technological spheres and, on the other hand, the partial orientation of the West itself in the socio-cultural, confessional, demographic and other spheres. In this vein, the so-called new great migration of peoples plays a key role. Previously, the main flows of migration were moving from the newly developed world to the "free", undeveloped, little-developed, weakly developed regions of the globe. Now these flows are moving in the opposite direction, from the less developed to the more developed regions: from all Asian and African countries to Europe and North America, from Latin America to the USA, from the CIS countries to Russia, from China - in industrially developed countries, Russia and the countries of Southeast Asia, etc. Of course, migration is an objective process, which is very difficult, let's say, impossible to stop. Moreover, migrants make a more or less significant contribution to resolving a number of key demographic, economic and other problems of the developed world. But at the same time, the masses of migrants are able to cause, on the one hand, the socalled demographic aggression, and on the other hand, what is called in literature a "defensive racism". As already noted, it was the issue of placement of migrants that became one of the factors of the split between the old and the new Europe. It is precisely these tendencies that largely explain the successes of the right-wing forces campaigning under nationalist slogans in elections in some Western European countries

\section{The Inversion of the Vector and Functions of Globalization}

The modern world information and ideological space turns into a battlefield for influence, power, prestige, into the arena of a global war of ideas, various models of social organization and ways of life, doctrines, images and authorities for redistribution of world markets, for world leadership. The American idea, the European idea, the Asian idea; Anglo-Saxon, Continental European, Japanese, Chinese, Singaporean models of capitalism - these are some of the currently interacting mutually complementary and simultaneously competing vectors for the development of the modern world.

In this context, the peculiarities of the mentality of the peoples of the Confucian-Buddhist world, which in some key components are more or less markedly different from the mentality of Western peoples, are of interest. In the sphere of theoretical constructions designed to explain the laws of the development of certain peoples, regions, cultural circles, civilizations, etc., in the $1960 \mathrm{~s}$, the thesis was popular, according to which Confucian ethics was declared the main obstacle to the modernization and economic development of East Asian countries. American sineologist J. Levenson in his works published in the late 1950's and 1960's, tried to substantiate the idea that by the beginning of the 20th century, Confucianism has become obsolete. In his opinion, in search of a new, comprehensive philosophical base, China chose communism, which represented "new Confucianism". According to him, communism has become a substitute for Confucianism. Justifying such position, he wrote: "Some compulsion seems to exist in many quarters to see Chinese communism not, indeed, as a foreign creed tamed down to traditional Chinese specifications,... but as Confucianism with another name and another skin but the same perennial spirit. Canonical texts and canonical texts, bureaucratic intellectual elite and bureaucratic intellectual elite-nothing has changed, allegedly-except, possibly everything". In this context, the following reasoning is of particular interest: "When traditionalists lost the will to develop tradition, and sought instead to repeat it, they changed its content. They saw it as an antithesis to the West, and development could only weaken it in that capacity. The strength which tradition would have brought them was lost" [12].

However, the last decades of the same century and the beginning of the XXI century in some countries before, in others -later its dynamic potencies were revealed. In the 1980s in the conditions of the rapid rise of the states of the region, it was precisely Confucianism that was regarded as almost the main factor of the rapid economic development of the so-called newly industrialized countries. For example, G. Roseman spoke of the East Asian Confucianism as a phenomenon equal to Western capitalism and European socialism. In his opinion, these three phenomena constitute cultural systems that compete with each other for world leadership. He emphasized such elements of Confucianism as discipline and frugality, which had a particularly favorable effect on modernization. According to this logic, the phenomenal growth of continental China, starting from the late 1970s, can be viewed as the result of the refusal of the communist regime from the Maoist ideology and a return to traditional Chinese culture. From such an assessment it could be concluded that an economic and technological breakthrough can be achieved with other values than Western values of human rights, freedom and democracy. Naturally, Roseman did not draw such a conclusion.

Unlike the Judeo-Christian and Islamic traditions, which are based on belief in one God, the socio-cultural matrix of the Confucian and Buddhist world is alien to monotheism. For the mentality of many peoples of the East, professing Confucianism, it is typical to have several beginnings entering into a dialogue with each other. As the Japanese researcher T. Ishida observes, the peculiarity of the Japanese tradition consists in believing in the immortality of the state, reaching its deification. Even the cult of the emperor derives from the belief that it symbolizes the immortality of the state [9].

Japan is distinguished by a special form of religious and cultural pluralism, distinct from Western forms. In the 
opinion of J. Masakadzu, Professor of the Osaka University, "Western pluralism, with its full integration of the various elements that have merged into it, can be compared with the alloying of metals or with a chemical compound. In contrast, in Japan, different elements, although they were in close contact with each other, still retained their identity, as is the case with mixed yarn fabrics" [13]. In Western cultural pluralism, homogeneous units or groups are based on a single foundation, for example, on Christianity (although in this latter, various directions and denominations are distinguished). In Japan, on the contrary, there is a pluralism of heterogeneous units or groups, the views of which are based on different grounds. The essence of Japanese pluralism is expressed in the combination and co-existence of different tastes, forms of mentality, customs, and styles of life in the same person. It is significant, for example, that many Japanese send rituals related to the birth of a child or marriage, according to the Shinto ritual, are buried according to Buddhist rites. Confucian morality prevails in their everyday life, and the values and norms of Christian ethics are rooted in many Japanese families. There is a commitment of one and the same person to one or other of the attitudes of two or more beliefs. It is believed that the Japanese Shinto plays an integrative role, Confucianism defines everyday morality, and Buddhism connects with the other world.

An important feature of the Japanese political culture is the adherence of the Japanese to group, collectivist and hierarchical norms and values. Unlike the Western model of democracy, with its emphasis on protecting the individual from the pressure of society and the state, the Japanese model emphasizes "the self-restriction of the individual, the desire to control his impulses, to integrate them into the system of public and state interests" [6]. In Japan, the syncretic mix of the moral and ethical teachings of Confucius and the most important elements of Shinto and Buddhism form the basis of the phenomenon that is commonly called the "Japanese spirit".

One can cite a number of other values, principles, attitudes that more or less significantly distinguish the paradigmatic foundations of the socio-cultural, spiritual, political, cultural and other components of the national consciousness of the Japanese people from the value system of Western peoples. Similar features are characteristic of the mentality of other peoples of the East. For example, in China, one of the Minsk emperors issued a special edict, according to which Confucius, Lao Tzu and Buddha were declared patrons of the Celestial Empire. The basis of the Chinese tradition is not only Confucianism, but also Legism, Taoism, Buddhism.

In this context, one of the paradoxes of globalization and the information revolution was that, as a result of the socioeconomic, technological, sociopolitical progress of the Western world, they began to undergo a kind of inversion, i.e. change their initial vector, purpose and function. Its essence lies in the fact that gradually they began to respond more and more to the interests of the rapidly rising East, understood in the broadest sense of the word.

The unprecedented economic and technological rise of the so-called new industrial countries, primarily China and Singapore, these authoritarian states, poses a number of sacred questions concerning the superiority of Western civilization in terms of socioeconomic and technological progress. Their experience has demonstrated with all evidence that peoples with an authoritarian system of government and other value systems are just like Western nations are able to adequately respond to new challenges of history and, what is especially important, the challenges of our time.

In general, the East Asian countries have achieved a kind of synthesis of tradition and modernity. Modernization was carried out with the preservation of the most important traditional principles in the socio-cultural and politicalcultural sphere. Values such as hierarchy, duty, consensus, subordination of the individual's interests to the interests of the group, adherence to the principles of corporatism in relations between people in the most important spheres of public life are of no small importance here. All this has little in common with the supremacy of liberal-individualistic values of human rights and freedoms, political democracy in their Western sense.

Here the Asian idea plays not the last role. As a special case of the Asian idea, in addition to the Japanese model (the "Japanese miracle"), Chinese, Singaporean and other models are being put forward that seem to challenge the American idea and the Anglo-Saxon market economy model. It is even said that the Washington Consensus is replacing by the Beijing consensus. Of course, this is a controversial issue, requiring independent research, corresponding to its significance. However, in the conditions of steady complication of the world economy as a unified system, it becomes increasingly difficult to determine which of these models adequately correspond to the socio-cultural and political-cultural matrix of each individual people.

\section{On the Unity and Fragmentation of the Modern World}

Given the realities of the modern world, there are sacramental questions: what is humanity - just an abstract concept or a single community Covering that embraces the whole world with a single identity, common characterological features, appearance, ethos, values, goals, ideal, mission, attitudes and interests common for all countries and peoples? Who determines all these qualities? Where are the tables on which they are engraved? Etc.

When searching for answers to these and many questions arising from them, each time an irresistible answer arises, the essence of which is that a single mankind with a complex of above-named components can be imagined, figuratively speaking, from a bird's flight. With such a vision, "humanity" is an abstract, metaphorical concept, uniting highly heterogeneous, contradictory, conflicting, warring communities with each other, pursuing different, often opposite interests and goals. Even the purely biological 
concept of the "instinct of self-preservation" representatives of different national and cultural traditions, peoples, faiths, etc. interpreted in different ways. The lower we descend to the ground, the more clearly we can see its fragmentation, patchwork, multicolor, diversity, against the backdrop of many examples of not only living together in peace and harmony, interrelations and cooperation, but also constant contradictions, mutual distrust, fear, enmity, conflicts, confrontation, wars, etc.

Have not different nations at all times fought each other for life and death, sometimes arranging large-scale collective dances of death on a world scale? Where is the guarantee that their nature, ethos will radically change and they will acquire the ability to achieve true unity and ensure peace and security for the whole world? In other words, many such sacramental questions arise, to which few can give any reasonable answers.

Humanity, of course, has a certain set of fundamental values, for example, on which its very survival as a species and the ensuing set of other interests depend. First of all, the peoples must fight against the universal thermonuclear war, resist all sorts of natural disasters, protect the natural environment of human existence, and so on. However, even these values, the range of which is very narrow, are understood by different peoples in different ways. In today's world there is no single understanding of even such values as human rights and freedoms. Some peoples view human life as the highest value, and a person as a measure of all things and legally abolished the death penalty. Other nations hold different positions, up to the protection of rudiments of talion law.

In addition to the named and some related goals and interests relating to the collective self-preservation of humanity throughout the entire written history there was not, could not be and cannot be one, acceptable to all peoples, cultures, communities system of values, ideals, moral and ethical norms and stereotypes of behavior, etc. This is also true of the values of human rights and freedoms, as well as political democracy, which can be described as the highest achievements of Western humanity. Even when accepted by the peoples of other regions, they are realized only in their historical forms, in different ways among different peoples, communities, and cultural circles.

According to one parable, Gypsies once lived in India. Then they had a certain goal, and they removed from their homes and went on a journey to find her. In the end, they forgot their goal and now wander aimlessly around the world. The same thing can be said metaphorically about humanity. It did not know, does not know and will not know where it came from, where it is going, what its mission is, and to what, ultimately, will come.what, ultimately, it will come.

Moreover, mankind did not and could not have any history that was unified for all peoples and countries, at least, in the periods preceding the Great geographical discoveries. In antiquity, it consisted of many civilizations and peoples, some of whom often simply did not know about the existence of each other. In fact, there were several parallel stories of human societies, stories that did not move along one straight line, although it is possible to establish certain lines of intersection between them. It is symptomatic that until the middle of the XIX century. the basis of the policy of the Celestial Empire was mythology, according to which there are no more civilizations outside of China, and those who live outside it are barbarians, the Chinese emperor, by virtue of the heavenly mandate, has a jurisprudence over the rest of the world. For many thinking Chinese, the inconsistency of this mythology became finally obvious only as a result of the so-called opium wars of the nineteenth century, in which the United Kingdom, having won the victory, seized a number of Chinese territories, including Hong Kong.

In this sense, the history of mankind could be portrayed as a path strewn with past systems of values, beliefs, truths. In this sense, history is in some way a set of accidents that the human mind painfully tries to drive into the Procrustean bed of patterns artificially constructed by itself.

There is a dual process of closing, on the one hand, and increasing the openness of the world, on the other. The world seemed to be closed within the globe, becoming a single, indivisible Oikumene, but at the same time it did not cease to be, but, on the contrary, it became even more open infinity, the diversity and multivariance which cannot be laid in the Procrustean bed of any kind of rational scheme. The world becomes simultaneously more uniform and more diverse, some opportunities grow, while others decrease. More standard forms of existence are the result of those innovations that inform people of the potential to do different things and differently arrange their lives. According to the well-known French sociologist of the end of the 19thbeginning of the 20th centuries E. Durkheim, the reduction of collective diversity in modern times between regions, nations and classes, was compensated by the increase in diversity at the individual level. For the world of these days, this thesis has acquired even greater significance. Homogenization of economic relations, technological and industrial production processes is accompanied by significant differentiation at the regional, national and subnational levels.

Therefore, a single world order is possible only as an open, dynamic space for the free coexistence of diverse nations, cultures, religions, forms of worldview, value and regulatory systems, etc. J.-J. Rousseau said: "I am like everyone else. I do not like anyone". In both cases the French thinker was right, since we are all the same according to the human nature, and at the same time we are different in the forms and ways of realizing this nature. Every nation, as well as every individual person, has its own understanding of good and evil, just and unjust, right and wrong and therefore attempts to find objective grounds and justifications for them are associated with unsolvable antinomies.

It seems that in this matter one can agree with the English philosopher I. Berlin, who wrote that "a society in which people are not the product of a particular culture do not have relatives and friends, who do not feel closeness to any particular people... and do not have a related language, then there is a threat of drought and the disappearance of 
everything that makes a person a person". In his opinion, if many languages are replaced by a single universal language, which is unlikely to give all people of the Earth the opportunity to express shades, emotions, inner life, this would mean not the creation of a universal culture, but the death of culture [2].

Despite the high degree of intensity of movement of natural resources, goods and information, linguistic and cultural barriers, traditions, customs remain an important obstacle to the acceleration of the processes of unification and cosmopolitanization, as well as large-scale migration of the population, etc. It cannot be denied that in the world, especially in the West, there are many cosmopolitan-oriented people who call themselves citizens of the world. But still, the overwhelming majority of people continue to consider themselves to be representatives of a particular nation. They are not yet ready to consider themselves as representatives of abstract humanity, some abstract people deprived of basic ethno-national, anthropological, cultural and other attributes.

Uniform cosmopolitan world is an unattractive place to live. This is especially true of the modern world, for which a new, immeasurably higher level of complexity and diversity is characteristic. Therefore, as the well-known German philosopher K. Jaspers rightly pointed out, "the universal world order that is mandatory for everyone (unlike the world empire) is possible only if the numerous beliefs remain free in their historical communication, without composing a single, objective, significant content of faith" [10]. This means that diverse cultures and beliefs do not exclude, but, on the contrary, supplement and reinforce each other. Taking these arguments into account, the binding principle of the unity of mankind is represented by the Golden Rule worked out over millennia by all small and great nations. The Golden Rule, as I. Kant formulated it in the Categorical imperative: "Treat other people as you want them to treat you". This is the idea of an autonomous ethic, according to which moral principles are eternal and do not depend on historical conditions. According to Kant, every single person is the highest value and, having a sense of dignity, has the right to defend himself against any encroachment by any external force. Accordingly, a person is endowed with the freedom to choose the forms of behavior through the prism of the perception of another person. At the same time, any of his actions are evaluated on the basis of the notions of good and evil. There is no perfect person by nature, which could be the standard of these qualities. Consequently, the notions of good and evil have passed to man from God himself, who is their only bearer. It is appropriate to add that each people has their own understanding of God and the divine, Satan and satanic, respectively, good and evil.

In today's manifold, polycentric world, all great and small nations, their cultures, values and beliefs that they hold are of equal importance for mankind. Differences, specificity, uniqueness, singularity do not always and do not necessarily mean backwardness from the so-called advanced cultures, and do not necessarily strive to catch up, surpass or exceed them. It is not entirely correct to divide history into good and bad, light and dark periods, to lower and higher stages from the point of view of moral perfection and imperfection of peoples. In this sense, apparently, N.S. Trubetskoy was right when he said that, there is no "cultural ladder". "The moment of evaluation", he believed, "must be permanently banished from ethnology and the history of culture, as well as from all evolutionary sciences, for the evaluation is always based on egocentrism. There are no higher and lower. There are only similar and dissimilar. To declare those who look like us higher, and those who are different - inferior - arbitrarily, unscientific, naive, finally, just silly" [17]. Each historical epoch had its ups and downs, its light and dark sides, its saints and fallen ones, heroes and scoundrels, its own criteria of good and evil, justice and injustice, radiant peaks and gaping abysses, their understanding of the divine and satanic, etc. Economic and technological progress is not always and necessarily not followed by progress in the moral sphere. As evidenced by the historical experience of mankind, the inverse proportion of progress in the material sphere and regression, degradation in the sphere of the spirit is not ruled out. Exponential growth itself, which has become a dynamic regularity of the modern world, excludes rectilinear extrapolation of modern realities for the future and enhances the possibility of multi-vector or, more precisely, multivariate processes of its socio-political development and, accordingly, the configuration of geopolitical forces in the emerging or already formed polycentric world order. It seems that it is on the recognition of this truth that ways can be found to achieve a real unity of the modern world.

It is noted that the socio-cultural and spiritual heritage is very difficult to transplant to a different cultural environment. The characterological components of the world view of each individual people are embodied in the national historical tradition. They can be strengthened, enriched and honed with life practice, but very difficult to transfer from one people to another.

For example, technology, created by a representative of a particular people, is inherently universal in nature, as such it is aimed at mass production everywhere, it does not know national or other political and geographical boundaries. As French sociologist of the XIX century G. Lebon noted, "the discoveries owed to the mind constitute the common heritage of mankind; advantages or disadvantages of character constitute the exclusive property of each people. It is an immutable cliff in which the wave must be beaten day after day for centuries, to grind only its contours; it corresponds to the specific character of the people, the fin of the fish, the beak of the bird, the tooth of the carnivore" [Lebon, G. 1898:29]. Or, as the well-known American-English poet T.S. Eliot figuratively expressed, democracy is something like a combination of machine and plant. Moreover, if the machine symbolizes the principle of universality, equally manifested in all countries, then the plant is a principle of uniqueness, accentuated in every national culture. It is precisely this combination of uniqueness and universalism that we find in the transformation of the modern East.

Here, naturally, the question arises: why only nowadays 
has the willingness of the East been revealed to accept and integrate the scientific, technological and economic achievements of the West? This is a complex issue requiring comprehensive and independent consideration.. One can only note that technology operates with things and concepts lying on the surface, it has an impersonal, universal character, it is aimed at typicality and mass character, possibility of widespread use. Therefore, it can be borrowed and mastered, successfully used without putting yourself at risk of spiritual enslavement, which, in turn, makes it available to virtually all peoples. But technology has, if not direct, then, at any rate, an implicit influence on social forces, awakening in them some hidden potentialities which for the time being did not show a visible readiness or desire to perceive and master technological innovations. An example of the countries of the Asia-Pacific region shows that the irresistible spread of the technological achievements of the Western world, to which in the East in general and in the Asia-Pacific region in particular, for a long period of time showed a steady immunity, yet ultimately contributed to the maturation of their "moment of truth" or the "X-Hour": They not only mastered the latest technologies at the highest point of their development, but also made a powerful breakthrough in the development and implementation of these technologies. Another question: why for most countries in the region it was symptomatic that the new industrial countries literally revolutionized the theory of economic growth, demonstrating to the whole world the opportunity to jump over the industrial and post-industrial phase and immediately immerse themselves in the information economy.

In this connection, the following example is of interest. An attempt by the West to seize Japan and China in the XVIth and XVIIth centuries ended in failure. Western aliens were expelled overseas, from where they came, and Japan, China and Korea were closed. The West managed to achieve in the XIX century what it failed in the XVI-XVII centuries. A. Toynbee saw the reason for it in the fact that the challenge facing the Far Eastern nations was different in each case: "In the XIX century, Western civilization appeared before them primarily in the guise of an unfamiliar new technology, in the XVIth century it appeared in the guise of a new unfamiliar religion" [16].

In fact, there is a similar situation today. The non-Western world is ready to accept Western knowledge, certain principles and institutions of the market economy, high technologies, some external attributes, such as clothes, manners, mass culture, etc. However, as they say, it is the synthesis of the "Japanese spirit" with the Western technical genius, according to the formula "Japanese spirit + Western technology" that resulted in the "Japanese miracle", putting the Land of the Rising Sun on the first roles in the world economy. In this matter, Ayatollah Khomeini was right, who told the correspondent of the Italian newspaper Corriere della Sera, Oriana Fallaci: "things are a good side of the West... We are not afraid of your science or your technique. We are afraid of your ideas and your customs. Politically and socially this means that we are afraid of you... From now on we will oppose all those who provoke us to the right and left, here and there" [7].

\section{Conclusions}

In assessing these realities, it is especially important to take into account the fact that there is a mismatch between the vectors of economic and technological globalization, on the one hand, and political realities, the essence of which is manifested in the resistance of peoples to the tendencies and processes of weakening and even the loss of state sovereignty and national identity, on the other. In other words, although the economy that does not recognize state borders has become global, the political sphere does not lend itself well to the processes of globalization, since it is permeated with value, socio-cultural, political and cultural principles, rooted in the depths of self-consciousness of peoples. They cannot but complicate the search for a balance between the national and supra-national principles of self-organization and the functioning of society and the state.

Of course, mankind and every single nation are related to each other as a kind to the species and, in this sense, the abstract sphere of the universal mankind is wider than the sphere of individual tribes, nations. But without these latter, humanity itself in the real sense of this word does not exist and cannot exist. This ratio is figuratively characterized by the nineteenth-century Russian thinker N.Y. Danilevsky, who claimed: "The attitude of the national to the universal does not at all resemble the narrow courtyards or cages surrounding a vast area, and can be likened to streets intersecting around the square, which for each street is only part of it and equally belongs to all streets, and therefore is smaller and narrower than each of them separately". which in each street constitutes only a part of it and equally belongs to all streets, and therefore less and more closely each of them separately". Comparing the city with humanity as a whole, he came to the conclusion that with this understanding "there is nothing left to do but to rebuild your street according to your own plan, and not to crowd in the general area and not to take up the continuation of another's street... and so do not deprive the city appropriate diversity and spreading in all directions" [5].

Simplification, uniformity lead to regression and dying of human communities, and diversity is the guarantee of their progress and prosperity, guarantee of their vitality. In the multi-dimensional realities of the modern world, value systems cannot but be multidimensional. Value systems are rooted not only in the socio-economic and political spheres, they lie deeper than politics and economics, forming an invisible basis for the latter. Therefore, it is obvious that in modern realities it can be not only about social and political pluralism, but also about the pluralism of socio-cultural, ethno-national, confessional, value etc. systems, Realizing this, it is necessary to recognize the reality of spatial pluralism and multi-structure of life of different peoples, nations, human communities. Characteristic components of the modern world can develop in different regions and 
countries with different economic, social, political and other results.

It is hardly legitimate to speak also of a unified system of world governance, capable of controlling, regulating and harmonizing global processes. For such a system, a single system of values, a single mentality and a universal ideology would be necessary for all peoples and cultural circles. But the world is too many-sided, too vast and complex, too rich to grow too quickly and becomes literate and able to open and master new opportunities so that they can be managed from one single center. Almost no instance has a chance to establish its hegemony over such a world.

As they say, you need to look at the world soberly, even if you do not like it at all. This is the essence of politics as an art of the possible. Peoples have that humanity that they have, no other humanity exists. And peoples need to take it as it is. The world proscenium on which it exists and operates can be viewed as a kind of grandiose market where myriads of subjects - peoples, nationalities, ethnic groups, tribes, diverse communities, institutions, organizations, movements, corporations, individuals, etc., collide. Naturally, each of these subjects pursues its own interests, which often do not coincide with the interests of other members of the world community. Here, contradictions, competition, conflicts, wars are the manifestations of the natural behavior of the subjects of world politics, guided by the desire to search for and approve their place, the status with which they relate selfesteem, ambition, selfishness, etc. Often this is, as F. Nietzsche said, the will to power (Wille zur Macht), the desire to take the leading position in the group, the collective, the society, the state, the scale of the world community, etc. Here the most capable and adapted to life really win. The theoreticians G. Spencer, W. Bagehot, L. Gumplowicz, W. Sumner and others who formulated this principle were not fools and misanthropists.

This is only one side of the problem. The other side is that human communities from small groups and collectivities to world powers and civilizations are doomed to perish and disappear without humanism, cooperation, harmony, commitment to peace, and so on. In other words, human communities and humanity as such cannot do without those moral and ethical values that make up those bonds that ensure their unity and viability. The life realities of peoples and their communities are formed in the space of the intersection of these two principles.

\section{References}

[1] Bauman, Z. 1997. Glocalization or to whom globalization, and to whom the location (In Polish language) // Sociological studies, 1997, №3:54-68.

[2] Berlin, I. 1996. Four Essays on Liberty. London and New York: Oxford University Press.
[3] Cerny, Ph. G. and Prichard, A. 2017. The new anarchy: Globalization and fragmentation in world politics. First Published June 20, 2017. Available: https: //doi.org/10.1177/1755088217713765

[4] Council of Europe: there is no longer a single force that can decide for everyone (In Russian). November 29, 2014. Available: http: //news.mail.ru/politics/20302899.

[5] Danilevsky, N. L. 1989. Russia and Europe. Moscow: Kniga.

[6] Democracy in Japan: Experience and Lessons (In Russian). 1991. Moscow: Nauka.

[7] Fallaci, O. 1989. Anger and pride (In Italian) // Corriere della sera, Sepeber 26, 1979.

[8] Gonzalez, P. 2017. The walls of Europe (In Spanish) // La Vanguardia, March 7, 2017.

[9] Ishida, T. 1983. Japanese Political Culture: Change and Continuity

[10] Jaspers, K. 1991. The Meaning and Assignment of History (In Russian). Moscow: Political Literature Publisher.

[11] Lebon, G. 1898. Psychology of Nations (In Russian). Moscow: Publishing House "Sytin Partnership"

[12] Levenson, J. R. 1958. Confucian China and Its Modern Fate: The Problem of Intellectual Continuity. Berkeley: University of California Press. New Brunswick, N. J.: Transaction Books.

[13] Masakazu, Y. 1986. Pluralism in der Kultur. Japan in der Westen. Frankfurt-a.-M.: Campus Verlag

[14] Rachman, G. 2017. Angela Merkel`s blunder. Donald Tramp and the end of the West // Financial Times. May 29.

[15] Rosenau, J. N. 2003. Globalization and Governance: Bleak Prospects for Sustainability // Internationale Politik und Gesellschaft, №3.

[16] Toynbee, A. 1995. Civilization on Trial (In Russian). Moscow: Iris press.

[17] Trubetskoy, N. S. 1920. Europe and humanity (In Russian). Sofia: Russian-Bulgarian publishing house.

\section{Biography}

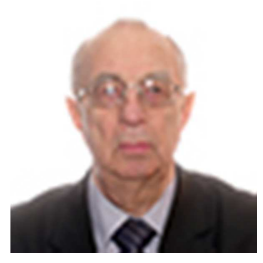

Kamaludin Gadzhiev. Graduated from Lomonosov Moscow State University (with honors). $\mathrm{PhD}$ and doctoral thesis defended on the theme "The history of US political thought." A number of monographs and many articles on this topic have been published. In recent decades, the circle of interests is political philosophy, political science and geopolitics.Dr.Sci. (Hist.), Professor, Chief researcher of the National Research Institute of World Economy and International Relations, Russian Academy of Sciences (23 Profsojuznaja St, Moscow, Russia, 117997). 